\title{
Prácticas Disruptivas e Intervenciones de Diseño en Estampación Digital, Imagen de Marca y Prototipado
}

\author{
Disruptive Practices and Design Interventions in Digital Stamping, Branding and Prototyping
}

\author{
Diana Rodríguez Barros \\ Universidad Nacional de Mar del Plata. Argentina \\ dibarros@mdp.edu.ar
}

\begin{abstract}
We present learning experiences related to Textile Design in postdigital environments, linked to disrupted practices from Design Thinking perspective, with the intention to translate it into sustainable didactic strategies. Methodologically from the workshop, we develop design and graphic's databases from textiles and digital printing methods, different media's applications, prototyping and identity simulation of their own business, which includes branding, communication pieces and packaging. We recognize innovative and meaningful responses from students regarding exploration, idea's generation and prototype's creation. As theachers, like craftsmen, we have tried to link material culture, tacit knowledge, resistances, social interaction and production methods.
\end{abstract}

Keywords: Design; Digital stamping; Practices disruptive; Teaching-learning experiences; Environment post-digital.

\section{Introducción}

Hemos observado, en el medio académico universitario, discordancias entre las competencias enseñadas a los estudiantes y las requeridas en la práctica técnica y profesional. Asimismo, detectamos currículas y planes de estudio relativamente rígidos, en conflicto para mantener efectividad y eficacia, así como para activar renovaciones profundas.

No obstante hay experiencias, que adhieren a prácticas de naturaleza disruptiva (Cobo Romaní y John Moravec (2011), y que están revertiendo esta tendencia en procesos de enseñanza aprendizaje desde entornos virtuales interconectados, que como bien los ha identificado Pardo Kuklisky (2010) remiten a categorías amplias del mundo postdigital.

En esta dirección, y encuadrados en la perspectiva del Pensamiento de Diseño (Brown, 2009) presentamos una serie de prácticas docentes centradas en computación gráfica orientadas hacia el tratamiento de la imagen digital y procesos proyectuales en los ámbitos del Diseño Textil. Estamos involucrados en estas tareas desde pasados ciclos lectivos, continuando con las mismas desde las reformulaciones, retrolimentaciones y actualizaciones que han tenido lugar (Rodríguez Barros, 2012; Rodríguez Barros, 2011).

Actualmente en esta dirección, estamos vinculando e interactuando con tres conceptos fuertes desde intervenciones de diseño y gestión. Primero, el concepto de estampación digital (Bowles \& Issac, 2009), como una particular operación vinculada al Diseño Textil sobre intervenciones de tintura parcial y/o total de la superficie de un tejido o hilado empleando uno o varios colores según de un motivo de dibujo junto a un patrón de repetición y continuidad. Segundo, el concepto de marca (Lamb. et.al, 2002), como variable estratégica de identificación de los productos que permite distinguir sus atributos y se refiere a un nombre, un término, una señal, un símbolo, o una combinación de alguno de éstos que genera una imagen identificatoria de productos $y$ servicios y los diferencia de otras similares. Tercero, el concepto de prototipado rápido (Schrage, 2000), como una materialización intermedia de producciones en entorno virtuales vinculada a procesos de innovación y comportamiento pragmático.

Nuestra intención es entonces continuar explorando, experimentando, profundizando y reflexionando sobre estas experiencias, en entornos virtuales interconectados, en incesante disposición de adaptabilidad y cambio. Lo hacemos con la intención de facilitar la reformulación de estrategias didácticas innovadoras y sostenibles, al decir de Juan Freire, 2012), inmersos en un protoparadigma en estado beta constante.

\section{Presentación del Caso}

Desde tal encuadre, presentamos una serie de prácticas de enseñanza aprendizaje desarrollladas en nivel 2 del Taller Informática Industrial, correspondiente al 3o año de la carrera de Diseño Industrial en las Orientaciones Textil e Indumentaria, de la Facultad de Arquitectura, Urbanismo y Diseño de la Universidad Nacional de Mar del Plata, Argentina. La temática se ha enfocado en el desarrollo del diseño y la gestión de bases de datos gráficos vinculadas a estampación digital, imagen de marca identitaria y prototipado rápido desde intervenciones de diseño, rediseño y fabricación. 
El curso fue realizado durante el segundo semestre del pasado ciclo lectivo del 2012, con una carga horaria de cuatro horas semanales. Participaron un total de sesenta y dos estudiantes quienes trabajaron en forma individual o en grupos de dos integrantes, conformando dos comisiones de trabajo con asistencia de tres docentes graduados y un adscripto alumno.

La experiencia ha sido desarrollada en el Laboratorio de Computación, a la manera de taller virtual. Según el enfoque que propone Donald Schön (1998), por un lado asumimos al taller como el ámbito donde se aprende haciendo y que permite que docente y estudiante se encuentran en una situación de trabajo activo con los objetos de conocimiento. Por otro, como ámbito donde se despliegan prácticas reflexivas que implican el aprendizaje desde la acción y la puesta en valor de la habilidad para la evolución permanente, junto al planteo y resolución de problemas complejos e impredecibles, difíciles de disipar con una única respuesta. En particular, el ámbito de nuestro taller ha sido de naturaleza postdigital donde hemos trabajado cocreativamente, explorando, generando ideas y finalmente fabricando prototipos

\section{Objetivos, Metodología y Técnicas}

Los objetivos del curso han estado orientados a reconocer, formular y optimizar metodologías avanzadas de trabajo con programas sobre diseño y edición de imágenes pixelares y vectoriales aplicados al diseño y gestión de bases de datos gráficos sobre estampación de textiles, estampado en soportes diversos, fabricación de prototipos, conjuntamente con la creación y gestión de la imagen de marca identitaria junto a piezas comunicacionales gráficas accesorias.

En particular y desde una mirada pragmática, hemos recurrido a técnicas de desarrollo de proyectos y de resolución de problemas, siguiendo a Stemberg, R. J. y Spear-Swerling, L. (1996), con la convicción de interpretar y conceptualizar a través de intervenciones y consecuencias de rasgos perceptibles $y$ verificables, en interacción directa con los objetos y los procesos involucrados.

Metodológicamente y según el encuadre del Pensamiento de Diseño, la experiencia ha reconocido una secuencia básica de recorrido en tres fases, con las necesarias instancias de revisiones, ajustes y retroalimentaciones en los diversos momentos de cada fase.

En primer lugar los estudiantes emprendieron el diseño y la gestión de las estampas, afrontando y resolviendo la búsqueda, el análisis, la selección y la catalogación de información gráfica sobre diseños textiles en la web según una tendencia definiendo estilo, destinatario y temporada dentro de una colección, familia, línea, serie; el redibujo o la vectorización de los elementos de las imágenes bitmap de las estampas seleccionadas; el diseño de los motivos desde los elementos vectorizados según la tendencia elegida; la creación y la aplicación de paletas de colores recurriendo a alternativas de monocromías o bicromías y según diferentes métodos de creación; la generación de unidades de repetición o rapports de las estampas, explorando diversos criterios de articulación, repetición y continuidad.

En segundo lugar, dentro de la tendencia, concepto, contexto, destinatario, usuario y temporada definida previamente, resolvieron la propuesta y el desarrollo de la simulación de un micro-emprendimiento, afrontando la creación y diseño de imagen de marca desde un abordaje amplio de construcción de la identidad y de la imagen corporative; precisaron la gráfica del nombre a manera de logo, isologo y/o isologotipo; resolvieron el estampado en soportes particulares dentro de la línea, serie y/o familia empleando diferentes objetos materiales tales como moldes, figurines, prendas, accesorios, utensilios, mobiliario, u otro tipo de objetos.

En tercer lugar, abordaron los procesos de fabricación recurriendo a técnicas de sublimado, desarrollando fichas técnicas, produciendo muestras junto a prototipos rápidos de los objetos y/o de las prendas estampadas. Complementamos con el diseño y la producción de piezas gráficas comunicacionales y accesorias de la marca, en soporte digital e impreso a la manera de catálogo, folletería, tarjetería y packaging primario, siempre dentro de la línea argumental que diera entidad a la comunicación con relación a la verosimilitud de la marca generada.

Por último desarrollamos presentaciones interconectadas a la Web de toda la documentación de lo producido en el curso, incluyendo procesos y productos tales como marca, estampa, aplicaciones, catálogo, fichas técnicas, paletas de colores, muestras, etc.

(Ver Figuras 1, 2, 3, 4. Presentamos el trabajo de la estudiante Maria Celina Monacchi dirigida por el equipo docente integrado por María Mandagarán, Claudia Ros, Gabriela Ramirez, Eugenia Molina, (año 2002), sobre intervenciones en estampación basados en la obra del artista plástico argentine Milo Lockett).

\section{Resultados}

Hemos registrado que los resultados mostraron diversidad de alternativas válidas en temáticas y aplicaciones próximos a metodologías ágiles, que han reconocido influencias de desarrollos de mejora inspirado en procesos, valorizando la cultura del prototipado junto al ensayo y el error; la capacidad de cambio y adaptación frente a la rigurosidad de la planificación; los ciclos cortos de iteración; la jerarquización de las experiencias de usuario por sobre procesos e instrumentos; el énfasis en los modos de trabajo y construcción colectiva propia de los entornos colaborativos Web 2.0, 3.0 y ubicua.

Hemos observado en los estudiantes, mayor responsabilidad, esfuerzo y capacidad de autogestión de su propio aprendizaje, en 


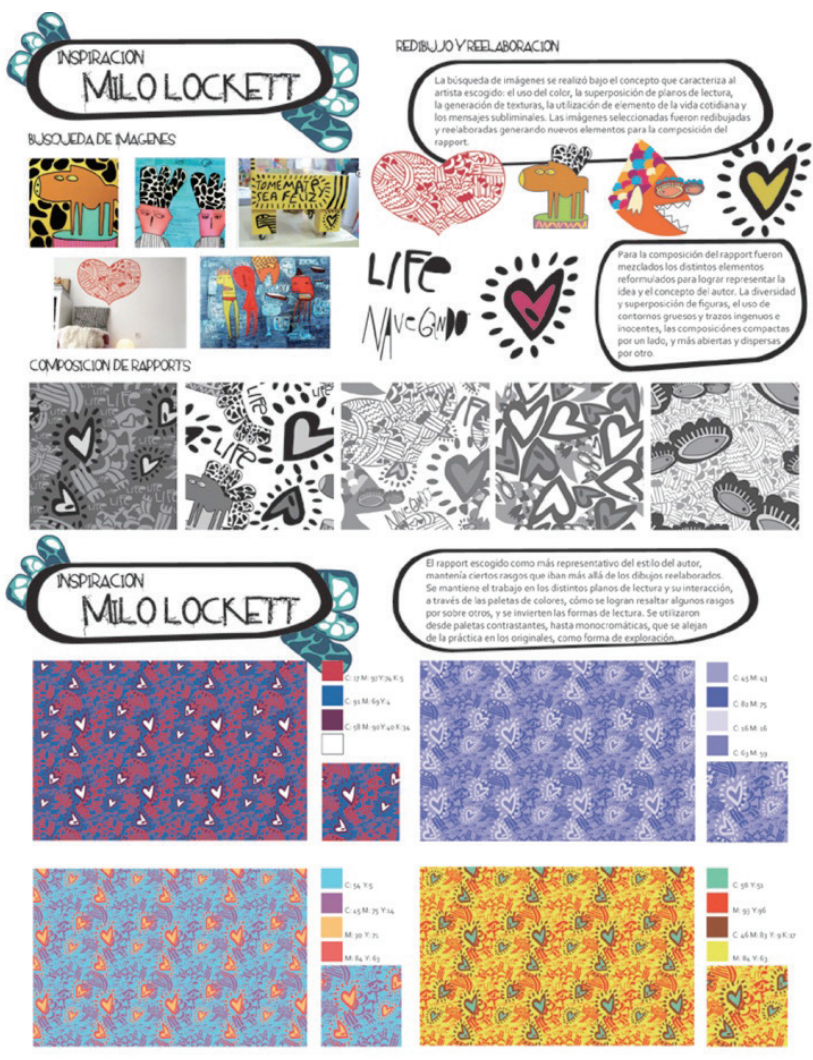

Figura 1: Referente Milo Lockett, redibujo y diseño motivo y rapport.

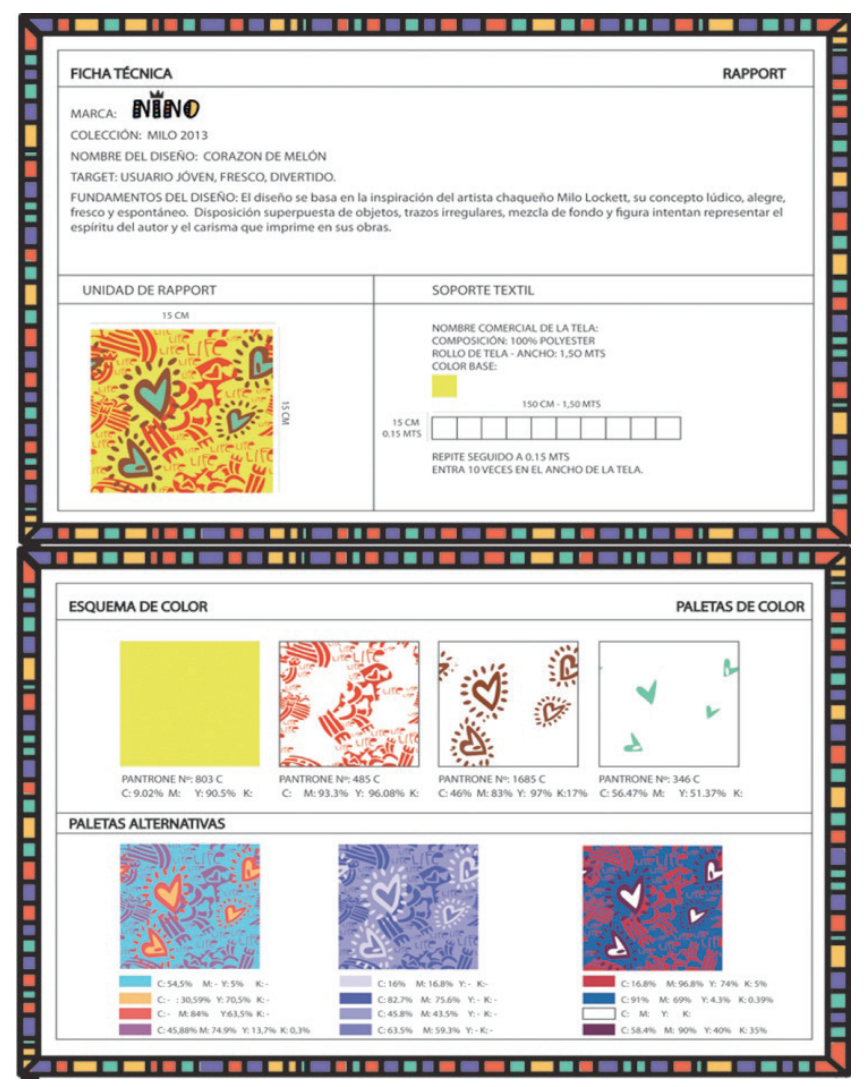

Figura 3: Ficha técnica, esquemas de color y paletas alternativas,
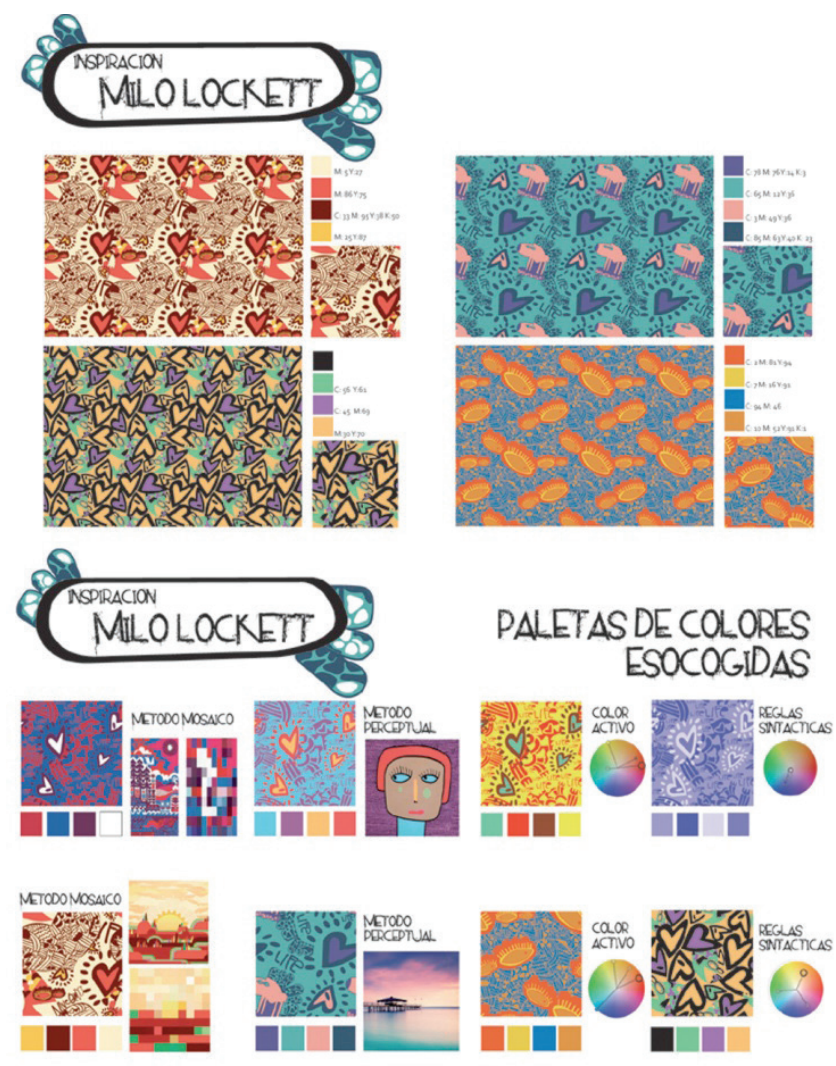

Figura 2: Diseño rapports alternativos y paletas color.
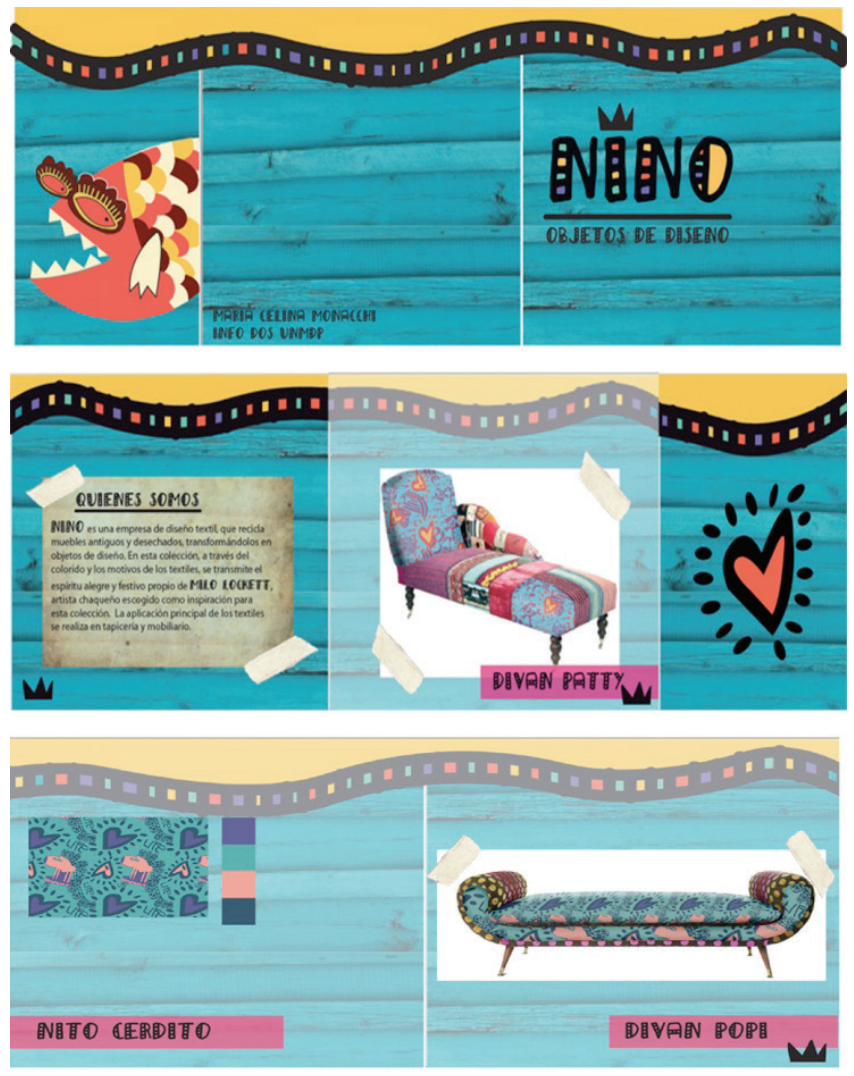

Figura 4: Portada desplegada catálogo y páginas interiores. 
tanto han aplicado en proyectos pseudo-reales las habilidades y conocimientos adquiridos en situaciones que los han desafiado a recuperar, comprender y aplicar lo aprendido para resolver problemas o proponer mejoras

En esta dirección, especialmente, fueron factores efectivos y dinamizadores, la posibilidad de trabajar según modalidades colaborativas e interactivas propias del medio postdigital, de desarrollar propuestas de diseño y de comunicación alternativas a las propuestas tradicionales, y de aplicar y transferir lo aprendido a otros ámbitos de la carrera.

De tal forma, valoramos como fructífera la experiencia, superando restricciones repetitivas y soluciones únicas en aprendizajes tradicionales y conductistas sobre programas de computación gráfica.

\section{Conclusiones e Implicancias}

Como conclusiones provisorias, reconocemos que asumimos la enseñanza del uso e incorporación de tecnologías sobre computación gráfica, en procesos de diseño de textiles, en una constante de cambio y estimulación. Lo hemos intentado hacer desde propuestas didácticas que renuevan el sentido inicial de simple aprendizaje instrumental, en tanto lo enriquecen y lo transforman, tendiendo hacia la estimulación del autoaprendizaje y del trabajo colaborativo.

Entonces, desde los entornos postdigitales nos interesa transformar el simulacro de la enseñanza en experiencia, con la intención de producir sentido y aprendizajes significativos. Coincidimos con Maria Acaso (2013) cuando sostiene que nuestra tarea, como docentes, implica desplazarnos de lo descriptivo a lo narrativo, de lo predecible a lo inesperado, de lo ajeno a lo personal, del texto al audiovisual, de los recursos visuales tradicionales a los recursos tansmediales actuales, de la memorización a la acción, del fragmento al nodo y la red, y fundamentalmente de lo pasivo a lo experiencial.

Por lo tanto, también nos preocupa e interesa asumir nuestro rol docente como expertos sociales y no aislados, que tratan a los demás y a sus contextos considerando su complejidad global, desde la posición del mentor y con deseo de transparencia. O sea, con la intención de afrontar los desafíos de las buenas prácticas docentes desde la experiencia que se construye a través del tiempo.

Al respecto y siguiendo a Richard Sennett (2009) aspiramos actuar a través de nuestras propias prácticas desde el oficio de artesanos. Lo intentamos hacer en los límites de nuestros ecosistemas educativos en tanto además inmersos en los entornos postdigitales interconectados. Desde allí abordamos cuestiones de diseño y de fabricación desde dinámicas docentes que, por un lado, mantengan intacta la cohesión interna de la práctica. Pero por otro, que permitan, siguiendo tendencias disruptivas, el intercambio, la fluidez, la innovación y la mezcla hibridada con el afuera. En definitiva, vinculando cultura material, conocimiento tácito, resistencias, interacción social e instancias productivas.

Por todas estas razones, nos interesa continuar explorando, interviniendo y profundizando este tipo de experiencias vinculadas con el Diseño Textil e Indumentaria, tanto hacia aspectos productivos de carácter sostenible, como hacia aspectos relacionados con la comunicación y el trabajo colaborativo en los entornos virtuales interconectados.

\section{Nota}

El grupo docente, bajo la dirección de la autora, ha estado integrado por Dis.Graf. María Mandagarán, Dis.Graf. Claudia Ros, Dis.Ind. Gabriela Ramirez y contó con la colaboración de la srta Eugenia Molina en condición de ayudante alumna adscripta.

\section{Agradecimientos}

El presente trabajo se encuadra en actividades de transferencia del proyecto de investigación bianual 15/B244 SCyT UNMdP 2012-2013 dirigido por la autora y radicado en los Centros CEAC y CIPADI FAUD UNMdP.

\section{Referencias}

Acaso, M. (2013). "La investigación como simulacro: lavadoras, mediterráneos y ecos vacíos". En Maria Acaso.es. Disponible URL http://tinyurl.com/pcdd5t7 (consultado agosto 2013)

Bowles, M. \& Issac, C. (2009). Diseño y estampación digital. Barcelona: Blume.

Brown, T. (2009) Change by design: how Desgn Thinking transforms organizations and inspires innovation. Harper Collins. New York.

Cobo, C. y Moravec, J. (2011). Aprendizaje invisible. Hacia una nueva ecología de la educación. Edicions Universitat de Barcelona. Barcelona.

Freire, J. (2012) "Ecosistemas de aprendizaje, emprendizaje e innovación" En nómada. Disponible URL http://tinyurl.com/p9rarew (consultado agosto 2013)

Lamb, Ch.; Hair, J.; McDaniel, C. (2002), Marketing, International Thomson Editores S.A., Pág. 301.

Pardo Kuklinski, H. (2010). Geekonomía. Un radar para producir en el postdigitalismo. Edicions Universitat de Barcelona. Barcelona.

Rodríguez Barros, D. (2012). “Diseño, Enseñanza y Prácticas Disruptivas. Marcos conceptuales de referencia". En Celani, G. et.al. edits. Libro Ponencias XVI Congreso Sociedad Iberoamericana de Gráfica Digital. Universidade Federal do Ceará. Fortaleza. Pp. 251-254.

- (2011). “Diseño textil y estampación digital. Un caso de enseñanza y práctica proyectual en entornos digitales". En Chiarella,M. y Tosello, M. Edits. Libro Ponencias XV Congreso Sociedad Iberoamericana de Gráfica Digital. Universidad Nacional del Litoral. Santa fe. Pp 406-409.

Schrage, M. (2000). Juego serio: Cómo simulan para innovar las mejores empresas . Harvard Business School Press \& Paidós. Barcelona.

Schön, D. (1998). El profesional reflexivo. Como piensan los profesionales cuando actúan. Paidos. Barcelona.

Sennett, R. (2009). El artesano. Anagrama. Barcelona.

Stemberg, R. J. y Spear-Swerling, L. (1996). "La comprensión de los principios básicos y de las dificultades de enseñar a pensar". En Enseñar a pensar. Santillana. Madrid. Pp.95-118. 